\title{
Corrigendum
}

\section{Increased Occupancy of Dopamine Receptors in Human Striatum during Cue-Elicited Cocaine Craving}

Dean F Wong, Hiroto Kuwabara, David J Schretlen, Katherine R Bonson, Yun Zhou, Ayon Nandi, James R Brašić, Alane S Kimes, Marika A Maris, Anil Kumar, Carlo Contoreggi, Jonathan Links, Monique Ernst, Olivier Rousset, Stephen Zukin, Anthony A Grace, Jae Sung Lee, Charles Rohde, Donald R Jasinski, Albert Gjedde and Edythe D London

Neuropsychopharmacology (2007) 32, 256. doi:I0.I038/sj.npp. I 301247

Correction to: Neuropsychopharmacology (2006) 31, 2714-2725. doi:10.1038/sj.npp.1301194

Following the publication of this article, the authors noted that the author names were incomplete. The complete and correct author list is above.
Dr Lee's affiliation during the writing of this paper was: The Russell H. Morgan Department of Radiology and Radiological Science, Johns Hopkins University School of Medicine, Baltimore, MD, USA. His current address is: Department of Nuclear Medicine, Seoul National University College of Medicine, Seoul, South Korea. 